\title{
Gentamicin-Induced Nephrotoxicity in Rats Ameliorated and Healing Effects of Resveratrol
}

\author{
Coşkun Silan, ${ }^{*, a}$ Özge Uzun, ${ }^{a}$ Nil Üstündağ ÇomunoǦlu, ${ }^{b}$ Sanem GoKçen, ${ }^{c}$ Selma Bedirhan, ${ }^{a}$ and \\ Müjgan $\mathrm{CENGIZ}^{c}$ \\ ${ }^{a}$ Department of Pharmacology, Faculty of Medicine, Düzce University; 81620 Düzce, Türkiye: ${ }^{b}$ Yeditepe University, \\ School of Medicine Department of Pathology; Istanbul-Türkiye: and ${ }^{c}$ University of Istanbul, Cerrahpaşa School of \\ Medicine, Department of Medical Biology; İstanbul, Türkiye. Received July 12, 2006; accepted October 6, 2006
}

In this study, we aimed to investigate the possible protective effect of resveratrol on gentamicin induced nephrotoxicity. Experiments were carried out in male Wistar rats weighing $200-250 \mathrm{~g}$. Gentamicin sulfate $(80 \mathrm{mg} / \mathrm{kg}$ per day i.p.), resveratrol $(10 \mathrm{mg} / \mathrm{kg}$ per day i.p.) and gentamicin together with resveratrol were administered for $6 \mathrm{~d}$. The animals were sacrificed $24 \mathrm{~h}$ after the last injection. Urine, blood samples and tissue samples were collected from the animals on the seventh day of the treatment before they were sacrificed. Kidneys were collected for histopathological studies and fixed in $\mathbf{1 0} \%$ buffered formalin solution. Tissue samples were stored at $-70^{\circ} \mathrm{C}$ in liquid nitrogen for the determination of glutathione (GSH), glutathione- $S$-transferase (GST), malondialdehyde (MDA) and catalase (CAT). Glutathione assay was determined by the method of Beutler et al. GST amounts were measured by the method of Habig et al. Catalase activitiy was tested by Aebi's method and MDA was determined according to Thayer's method. Blood urea level was significantly increased in the gentamicin treated group. The study showed lowered levels of urea and creatinine levels in resveratrol administered groups when compared with gentamicin administered rats, and the difference was statistically significant. It has been determined that resveratrol caused statistically significant decrease in lipid peroxidation and reduced the level of catalase. Histopathological examination showed that resveratrol prevented partly gentamicin induced tubular damage. The results histopathologically demonstrated that resveratrol has a protective effect against gentamicin induced nephrotoxicity, lipid peroxidation and cellular damage in rats.

Key words resveratrol; gentamicin; nephrotoxicity; lipid peroxidation; antioxidant

Gentamicin (GEN) is a very effective antibiotic in treating gram-negative infections. ${ }^{1)}$ Unfortunately it causes renal failure in $10-20 \%$ of therapeutic courses. ${ }^{2,3}$ It has been demonstrated that GEN-induced nephrotoxicity is characterized by direct tubular necrosis, which is localized mainly in the proximal tubule. ${ }^{4-6)}$ The exact mechanisms of GEN-induced nephrotoxicity still remain unclear. However GEN has been shown to enhance the generation of reactive oxygen species (ROS) ${ }^{4,7,8)}$ ROS have been suggested as a causative agent of cell death in different pathological states including various models of renal diseases. ${ }^{9-12)}$

Although a considerable number of studies have been devoted to the investigation of heart disease by antioxidants, the protective role of antioxidant in renal disease has been poorly analysed. ${ }^{13)}$ However, the protective effects of some antioxidants such as manganese chloride and lycopene were investigated against lipid peroxidation induced by GEN and cisplatin. ${ }^{14,15)}$ Furthermore, GEN induced nephrotoxicity was ameliorated by antioxidant vitamin $\mathrm{E}$ and garlic extracts. ${ }^{16,17)}$

Resveratrol (RSV) is a natural polyphenol phytoalexin (trans-3,5,4'-trihydroxy stilbene) and possesses diverse biochemical and physiological actions, which includes estrogenic, antiplatelet and anti-inflammatory properties. ${ }^{18,19)}$ In addition to these, resveratrol was found to exert its protective effect through upregulation of nitric oxide (NO) in kidney cells. $^{20)}$ Furthermore, it has a protective property against GEN induced lipid peroxidation and ameliorated glomerular filtration rate of renal blood flow and urinary excretion of $N$ acetyl- $\beta$-D-glucosaminidase. ${ }^{8)}$

In the present study, we aimed to investigate the possible effect of resveratrol, as an antioxidant agent, during the GEN treatment, which could prevent the drug induced renal tubu- lar necrosis, tubular vacuolization and parietal cell hyperplasia.

\section{MATERIALS AND METHODS}

Animals and Experimental Protocol Experiments were carried out in male Wistar rats weighing $200-250 \mathrm{~g}$, which were fed standard diet and water. The experimental protocols were approved by the Düzce Medical School, Animal Ethical Committee of Abant İzzet Baysal University, Düzce. Rats were randomly assigned to four groups. (1) Control group $(n=6)$; (2) RSV group that received a daily intraperitoneal dose of RSV $(10 \mathrm{mg} / \mathrm{kg})(n=6)$; (3) GEN group: these rats were treated intraperitoneally with the GEN (Bilim Pharmaceuticals, Istanbul, Turkiye), $80 \mathrm{mg} / \mathrm{kg}$ daily for $6 \mathrm{~d}(n=10)$; (4) Simultaneous treatment with RSV and GEN group: these rats were treated by RSV daily (i.p.) $(10 \mathrm{mg} / \mathrm{kg})(n=6)$ after the GEN injection. Rats were treated for $6 \mathrm{~d}$.

Sample Collection and Biochemical Assays After sacrifice of rats, both of the kidneys were dissected out for histopathological studies and fixed with \%10 buffered formalin solution in the room temperature. Tissue samples were stored at $-70^{\circ} \mathrm{C}$ liquid nitrogen for enzymatic analysis. Aortic blood samples were collected into tubes containing anticoagulant ( $2 \%$ sodium oxalate) agent. The blood samples were centrifuged at $200 \times \boldsymbol{g}$ for $5 \mathrm{~min}$ at $+4{ }^{\circ} \mathrm{C}$ to separate the plasma. Kidney samples were thawed and homogenized $(10 \% \mathrm{w} / \mathrm{v})$ in $0.15 \mathrm{M} \mathrm{KCl}$ at $4{ }^{\circ} \mathrm{C}$ and centrifuged at $10000 \mathrm{~g}$ for $90 \mathrm{~min}$. The supernatant was used as the source of experimental product. Glutathione (GSH) assay was determined by the method of Beutler et al. ${ }^{21)}$ with 5,5 dithio bis nitro benzoic acid as product. Glutathione-S-transferase (GST) 
Table 1. Effects of GEN Alone and Its Combination with RSV on Plasma Creatinine, Urea, $\mathrm{Na}^{+}$and $\mathrm{K}^{+} \mathrm{Levels} \mathrm{in} \mathrm{Rats}$

\begin{tabular}{|c|c|c|c|c|}
\hline Groups & Urea (mg/dl) & Creatinine $(\mathrm{mg} / \mathrm{dl})$ & $\mathrm{Na}^{+}(\mathrm{mEq} / 1)$ & $\mathrm{K}^{+}(\mathrm{mEq} / 1)$ \\
\hline Control $(n=6)$ & $20.5 \pm 1.38^{\dagger}$ & $0.33 \pm 0.01^{\dagger}$ & $140.7 \pm 0.67$ & $5.21 \pm 0.03$ \\
\hline Resveratrol $(n=6)$ & $21.8 \pm 1.76^{\dagger}$ & $0.35 \pm 0.10^{\dagger}$ & $140.8 \pm 1.01$ & $5.12 \pm 0.04$ \\
\hline Gentamicin $(n=10)$ & $135.7 \pm 5.07 * * *, \dagger$ & $3.16 \pm 0.14^{*, * *, \dagger}$ & $143.1 \pm 0.70$ & $4.79 \pm 0.02 *, * *, \dagger$ \\
\hline Gentamicin + resveratrol $(n=9)$ & $52.9 \pm 1.98 * * *$ & $1.18 \pm 0.034 * * *$ & $140.5 \pm 0.69$ & $5.1 \pm 0.04$ \\
\hline
\end{tabular}

Data expressed as means \pm S.E.M. The significance between two groups was determined with Dunnett's multiple comparison test, $* p<0.05$, statistical significant difference from the controls, $* * p<0.05$, statistical significant difference from resveratrol group, $\uparrow p<0.05$, statistical significant difference from GEN $+\mathrm{RSV}$ group.

Table 2. Effects of Resveratrol on Rat Kidney MDA, GSH Levels and GST, CAT Activities

\begin{tabular}{lccc}
\hline \hline \multicolumn{1}{c}{ Groups } & GSH (nmol/mg protein) & GST (nmol/mg protein) & CAT (k/mg protein) \\
\hline Control $(n=6)$ & $24.05 \pm 0.78$ & $22.55 \pm 1.41$ & $0.64 \pm 0.05$ \\
Resveratrol $(n=6)$ & $21.56 \pm 1.1$ & $18.55 \pm 2.75$ & $0.46 \pm 0.16$ \\
Gentamicin $(n=10)$ & $7.1 \pm 0.58^{*, * *, \dagger}$ & $7.16 \pm 0.64^{*, * *, \dagger}$ & $1.14 \pm 0.09^{*, * *, \dagger}$ \\
Gentamicin + resveratrol $(n=9)$ & $19.39 \pm 1.43^{*}$ & $18.0 \pm 1.44$ & $0.019 \pm 0.0066$ \\
\hline
\end{tabular}

Data expressed as means \pm S.E.M. The significance between two groups was determined with Dunnett's multiple comparison test. $* p<0.05$, statistical significant difference from the controls; $* * p<0.05$, statistical significant difference from resveratrol group, $\uparrow p<0.05$, statistical significant difference from GEN $+\mathrm{RSV}$ group.

amounts were measured by the method of Habig et al. ${ }^{22)}$ Rat kidney homogenate malondialdehyde (MDA) levels were measured by Thayer's method. ${ }^{23)}$ The catalase activity was performed by Aebi's method. ${ }^{24)}$ All the measurements were carried out by a spectrophotometry (Shimadzu 1601 UV-VIS spectrophotometer, Japan).

On the other hand, plasma creatinine, urea, $\mathrm{Na}^{+}$and $\mathrm{K}^{+}$ concentrations were measured by using an auto analyzer (Olympus AU 600, Japan).

Histopathological Examinations The kidneys were fixed in $10 \%$ buffered formalin and then placed in fresh fixative solution and fixed for 1 week. Kidneys coronally cut and half of each kidney selected for pathological examination was processed for paraffin wax embedding. Four $\mu \mathrm{m}$-thick, sagittal slides from each kidney were taken from each block. Four sections were cut and stained with hematoxylin eosin for light microscopy using a conventional protocol. ${ }^{25}$ ) A pathologist, blinded to sample identity, examined all samples using light microscopy. A semi quantitative evaluation of renal tissues was accomplished by scoring the degree of severity according to previously published criteria. ${ }^{26)}$ For each renal section, whole slide was examined for parietal cell hyperplasia, tubular vacuolization, and tubular necrosis. Briefly, minimum of 50 proximal tubules associated with 50 glomeruli were examined for each slide and an average score was obtained. Severity of lesion was graded from 0 to 3 according to the percentage of tubular involvement. Slides were examined and assigned for severity of changes using scores on a scale of none (0), mild (1), moderate (2) and severe (3) damage, in which $(0)$ denotes no change; grade (1) changes affecting $<25 \%$ of tubular damage (mild); grade (2) changes affecting $25-50 \%$ of the tubules (moderate); grade (3) changes affecting $>50 \%$ of the tubules (severe).

Chemicals GEN (dissolved in saline) was obtained from Bilim Pharmaceuticals., İstanbul, Turkiye while RES (dissolved in \%20 ethanol) was obtained from Sigma (St. Louis, MO, U.S.A.).

Statistical Analysis The data were expressed as mean \pm S.E.M. and were analysed using one-way analysis of variance (ANOVA). The significance between two groups was determined by the Dunnett's multiple comparison test, and $p$ value of $<0.05$ was considered statistically significant. For the analysis of histopathological data, a nonparametric test for multiple comparisons (Kruskal-Wallis) was used. Differences were regarded as statistically significant if $p$ value was $<0.05$.

\section{RESULTS}

Effect of Resveratrol on Plasma Creatinine, Urea, and $\mathrm{Na}^{+}$and $\mathrm{K}^{+}$Levels GEN caused an elevation of plasma creatinine $[0.33 \pm 0.01(n=6)$ to $3.16 \pm 0.14(n=10)]$ and urea levels $[20.5 \pm 1.38(n=6)$ to $135.7 \pm 5.07(n=10)]$ when compared to control group (Table 1). RSV inhibited the increase of creatinine $[1.18 \pm 0.034 \quad(n=9)]$ and urea levels $[52.9 \pm 1.98(n=9)]$ significantly in the GEN treated group. $\mathrm{Na}^{+}$did not change significantly due to GEN or RSV. Additionally, $\mathrm{K}^{+}$levels decreased significantly [5.21 $\pm 0.03(n=6)$ to $4.79 \pm 0.02(n=9)]$ in the GEN administered group (Table 1).

Effects of Resveratrol on Kidney MDA, GSH Levels and GST, CAT Activities As shown in Table 2, GSH levels decreased in GEN treated rats [24.05 $\pm 0.78(n=6)$, to $7.1 \pm 0.58(n=10)]$. This decrease was prevented by RSV $[19.39 \pm 1.43,(n=9)]$ GST levels also decrease in the GEN treated group [22.55 $\pm 1.41(n=6)$, to $7.16 \pm 0.64(n=10)]$.

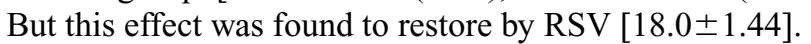

GEN caused an increase of MDA levels in kidney [0.022 $\pm 0.0025(n=6)$, to $0.047 \pm 0.0079(n=10)]$. Resveratrol was able to inhibit this increase significantly $[0.023 \pm 0.0044 \mathrm{nmol} / \mathrm{mg}(n=9)]$. We observed similar results in CAT activity. Elevation of CAT activity [0.64 \pm 0.05 $(n=6)$, to $1.14 \pm 0.09(n=10)]$ in GEN treated animals was found to decrease in resveratrol administered group $[0.63 \pm 0.07(n=9)]$.

Effects of RSV on Kidney Histopathology in GEN-Induced Nephrotoxicity Histopathological examination of kidney showed severe and extensive damage in gentamicin treated rats. These changes are summarized in Table 3. Figure $1 \mathrm{~A}$ indicates a kidney section of a control rat while Fig. $1 \mathrm{~B}$ shows representative images of kidneys of gentamicin treated rats which have tubular necrosis and edema (Fig. 1B). 
Table 3. Semi-Quantitative Analysis of Tubular Necrosis, Tubular Vacuolization and Parietal Cell Hyperplasia in Control, Resveratrol, Gentamicin Treated and GEN+RSV-Treated Rats

\begin{tabular}{|c|c|c|c|c|c|c|c|c|c|c|c|c|c|}
\hline \multirow{2}{*}{ Score } & \multirow{2}{*}{$n$} & \multicolumn{4}{|c|}{ Tubular necrosis } & \multicolumn{4}{|c|}{ Tubular vacuolization } & \multicolumn{4}{|c|}{ Parietal cell hyperplasia } \\
\hline & & 0 & 1 & 2 & 3 & 0 & 1 & 2 & 3 & 0 & 1 & 2 & 3 \\
\hline Control & 6 & 6 & 0 & 0 & 0 & 5 & 1 & 0 & 0 & 6 & 0 & 0 & 0 \\
\hline Resveratrol & 6 & 6 & 0 & 0 & 0 & 5 & 1 & 0 & 0 & 4 & 2 & 0 & 0 \\
\hline Gentamicin* & 10 & 0 & 2 & 7 & 1 & 0 & 1 & 6 & 3 & 0 & 3 & 6 & 1 \\
\hline $\mathrm{GEN}+\mathrm{RSV}^{* *}$ & 9 & 6 & 3 & 0 & 0 & 0 & 6 & 3 & 0 & 3 & 6 & 0 & 0 \\
\hline
\end{tabular}

$* p<0.05$, statistical significant difference from the control group and $* * p<0.05$, statistical significant difference between the GEN treated group and the GEN $+\mathrm{RSV}$ group Score 0: no degeneration, 1: mild degeneration, 2: moderate degeneration, 3: severe degeneration.

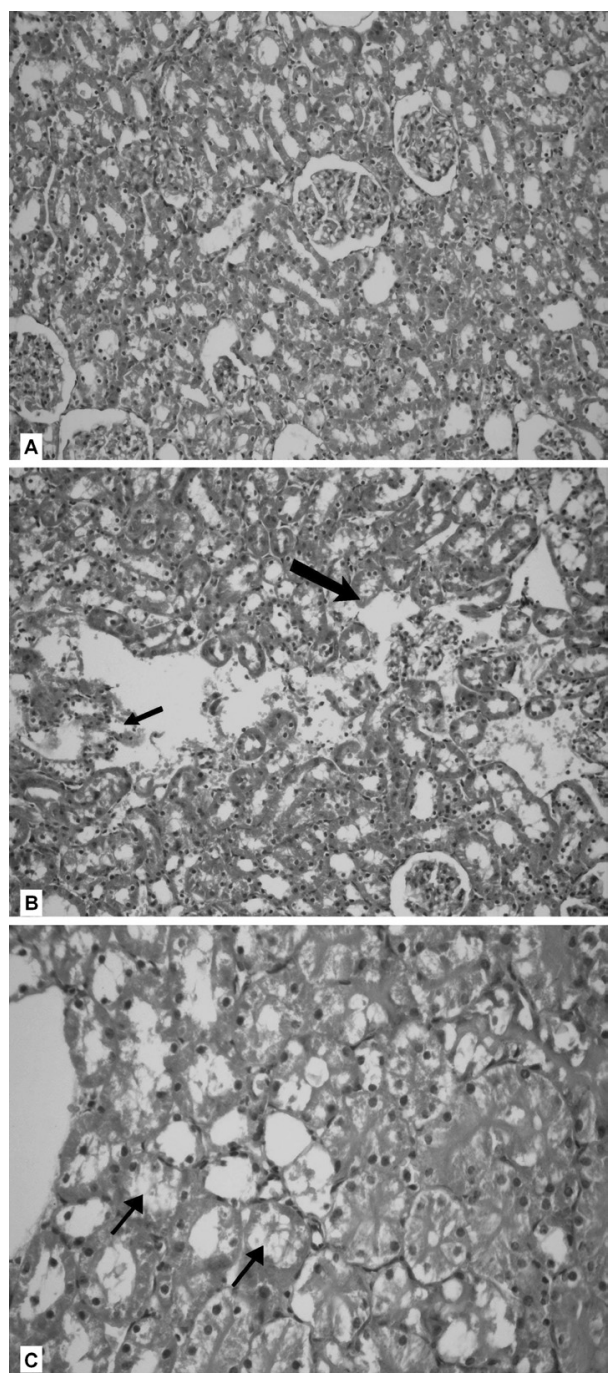

Fig. 1. (A) Light Microscopy of Renal Tissue from Rats

Control (renal tubules are normal) $(\mathrm{H} \& \mathrm{E} \times 100)$.

(B) Light Microscopy of Renal Tissue from Gentamicin Treated Rats

This representative image of kidney of gentamicin treated rats indicates tubulary necrosis (thin arrow) and edema (thick arrow) (Score-3), (H\&E $\times 100)$.

(C) Light Microscopy of Renal Tissue from Rats That Received RSV and GEN

This image showed simultaneous treatment with resveratrol and gentamicin. Tubular vacuolization (arrows) (Score-1), parietal cell hyperplasia (Score-1), $(\mathrm{H} \& \mathrm{E} \times 200)$

Tubular vacuolization, parietal cell hyperplasia and tubular necrosis are less severe in RSV treated rats (Fig. 1C, Table $3)$.

\section{DISCUSSION}

The results demonstrate that resveratrol treatment inhibited lipid peroxidation and CAT activity induced GST and GSH levels, ameliorated urinary functions (excretion of urea, creatinine, levels of $\mathrm{Na}^{+}$and $\mathrm{K}^{+}$), reduced the development of renal tubular necrosis and parietal cell hyperplasia, and attenuated tubular vacuolization.

GEN is a widely used aminoglycoside antibiotic and induced tubular necrosis. ${ }^{27-29)}$ Several reports have documented the pathogenesis of aminoglycoside-induced renal tubular cell injury such as derangement of lysosomal, mitochondrial and plasma membrane structure. ${ }^{30-32)}$ Furthermore, results of many studies have shown that the altered concentrations of various biochemical indicators of oxidative stress in kidney tissue are due to GEN. ${ }^{33-35)}$ Because of the obvious responsibility of ROS in GEN induced renal damage, several antioxidant agents have been used to block GEN nephrotoxicity. ${ }^{36-38)}$ In this study, we used a polyphenolic compound RSV, which was able to increase antioxidant capacity. ${ }^{39)}$

Aminoglycoside nephrotoxicity in experimental animals and in man was reported to cause reduction in serum potassium levels. ${ }^{40)}$ Furthermore, glomerular dysfunction due to GEN was correlated by increased levels of sodium in plasma. ${ }^{4}$ According to these data, we observed in our study that plasma sodium levels were augmented, while potassium levels were decreased. But administration of RSV to GEN treated rats resulted in an almost complete normalization. In addition to these data, we determined that RSV decreases elevated plasma creatinine and urea concentration in GEN treated rats. These results indicate that RSV could reverse the glomerular filtration rate in GEN treated rats. Our results are compatible with the study of Morales et al. ${ }^{8)}$ which demonstrated that RSV ameliorated renal plasma flow, renal vascular resistance and filtration fraction.

Oxidative stress is one of the causes of GEN-induced renal damage as mentioned above. GEN causes rapid changes in membrane lipid composition. These changes of membrane lipid composition may be induced by free radical-initiated lipid peroxidation. ${ }^{41,42)}$ This view is supported by increased MDA levels, one of the aldehydic products of lipid peroxidation, in GEN treated rats kidney. ${ }^{42-45)}$ We have found elevated lipid peroxidation in the GEN treated group, consistent with previous studies mentioned. The results also displayed that CAT levels are increased, while GSH and GST levels are decreased significantly in GEN-treated rats. These biochemical indicators of oxidative stress and antioxidant status were 
reversed by RSV. We assume that these findings are in accordance with the antioxidant effects of RSV. Furthermore these results are confirmed by the other studies, which have pointed to the inhibition of the development of renal failure by antioxidants in laboratory animals. ${ }^{16,46-48)}$

Free radicals give rise to membrane lipid damage and peroxides yields autocatalytic reactions. Plasma membrane damage results in loss of osmotic balance and intracellular calcium levels increase. Cellular swelling is the first manifestation of these reversible changes which can be detected under light microscope. Tubular vacuolization is the reflection of these reversible changes in kidneys. ${ }^{49)}$ In gentamicin group, we have observed tubular vacuolization in all samples, severe in 3 , moderate in 6 and mild in 1 cases. In G+RSV group, we have detected mild tubular vacuolization in 9 cases. We have observed a decrease in cellular damage level by RSV. Biochemical data were concordant with pathological findings in $\mathrm{G}+\mathrm{RSV}$ administered rats. In this group, $\mathrm{Na}^{+}$and $\mathrm{K}^{+}$values in serum were very similar to the control group. Continual cell injury accompanies some other reactions such as DNA lesions and protein-protein cross-linkages. If intracellular free oxygen radicals increase, irreversible cellular injury process begins. Lysosomal enzymes activated and irreversible cell injury microscopically observed as tubular necrosis of kidney occurs. ${ }^{49)}$ Scavenging of free oxygen radicals prevent irreversible cell injury and necrosis. A certain kind of enzymatic and non-enzymatic systems inactivates free radical reactions. These are antioxidants, iron, copper and a series of enzymes acting as free radical-scavenging systems and breaking down hydrogen peroxide and superoxide anion. The enzymes are catalase, superoxide dismutases and glutathione peroxidase. ${ }^{49}$ As we have evaluated tubular necrosis as a sign of irreversible injury. We have observed this finding in all cases of gentamicin group. In one case tubular necrosis was severe, in 7 cases moderate and in two cases mild. RSV as an antioxidant, inhibits lipid peroxidation and prevents cell injury. We have demonstrated that RSV decreases tubular necrosis, an irreversible cell damage. We have observed that RSV treatment affected biochemical values and pathological findings, in accordance. Resveratrol prevented the decrease in GSH and GST levels, and the increase in MDA levels and CAT activity. In the same way, RSV prevented reversible cell damage such as tubular vacuolization, and irreversible cell damage such as tubular necrosis. According to the pathological results, it can be stated that RSV can be protective for degenerative injury caused by gentamicin treatment. ${ }^{49)}$

In conclusion, it has been shown that ROS participate in GEN-induced kidney injury and treatment with RSV reduces lipid peroxidation and increases antioxidant status. The free radical-scavenging properties of RSV are the basis of decreased tubular necrosis, tubular vacuolization and reduced parietal cell hyperplasia in GEN treated rats. Therefore, we conclude that RSV decelerates the development of GEN induced nephrotoxicity in rats.

\section{REFERENCES}

1) Ho J. L., Barza M., Antimicrob. Agents Chemother, 31, 485-491 (1987).

2) Smith C. R., Baughman K. L., Edwards C. Q., Rogers J. F., Lietman P. S., N. Engl. J. Med., 296, 349-353 (1977).
3) Walker P. D., Shah S. V., Am. J. Physiol., 253, C495-499 (1987).

4) Cuzzocrea S., Mazzon E., Dugo L., Serraino I., Di Paola R., Britti D., De Sarro A., Pierpaoli S., Caputi A., Masini E., Salvemini D., Eur. J. Pharmacol., 450, 67-76 (2002).

5) Eisenberg J. M., Koffer H., Glick H. A., Connell M. L., Loss L. E., Talbot G. H., Shusterman N. H., Strom B. L., Ann. Intern. Med., 107, 900-909 (1987).

6) Pedraza-Chaverri J., Gonzalez-Orozco A. E., Maldonado P. D., Barrera D., Medina-Campos O. N., Hernandez-Pando R., Eur. J. Pharmacol., 473, 71-78 (2003).

7) Yanagida C., Ito K., Komiya I., Horie T., Chem. Biol. Interact., 148 139-147 (2004).

8) Morales A. I., Buitrago J. M., Santiago J. M., Fernandez-Tagarro M., Lopez-Novoa J. M., Perez-Barriocanal F., Antioxid. Redox Signal, 4, 893-898 (2002).

9) Shah S. V., J. Clin. Invest., 74, 393-401 (1984).

10) McCord J. M., Roy R. S., Schaffer S. W., Adv. Myocardiol., 5, 183189 (1985)

11) Grune T., Sommerburg O., Petras T., Siems W. G., Free Radic. Biol. Med., 18, 21-27 (1995).

12) Baliga R., Ueda N., Walker P. D., Shah S. V., Drug Metab. Rev., 31, 971-997 (1999).

13) Rodrigo R., Bosco C., Comp. Biochem. Physiol. C. Toxicol. Pharmacol., 142, 317-327 (2006).

14) Atessahin A., Karahan I., Yilmaz S., Ceribasi A. O., Princci I., Pharmacol. Res., 48, 637-642 (2003).

15) Atessahin A., Yilmaz S., Karahan I., Ceribasi A. O., Karaoglu A., Toxicology, 212, 116-123 (2005).

16) Fryer M. J., Redox Rep., 3, 259-261 (1997).

17) Pedraza-Chaverri J., Maldonado P. D., Medina-Campos O. N., Olivares-Corichi I. M., Granados-Silvestre M. A., Hernandez-Pando R., Ibarra-Rubio M. E., Free Radic. Biol. Med., 29, 602-611 (2000).

18) Bertelli A. A., Giovannini L., Bernini W., Migliori M., Fregoni M., Bavaresco L., Bertelli A., Drugs Exp. Clin. Res., 22, 61-63 (1996).

19) Ferrero M. E., Bertelli A. A., Pellegatta F., Fulgenzi A., Corsi M. M., Bertelli A., Transplant. Proc., 30, 4191-4193 (1998).

20) Giovannini L., Migliori M., Longoni B. M., Das D. K., Bertelli A. A., Panichi V., Filippi C., Bertelli A., J. Cardiovasc. Pharmacol., 37, 262-270 (2001).

21) Beutler E., Duron O., Kelly B. M., J. Lab. Clin. Med., 61, 882-888 (1963).

22) Habig W. H., Pabst M. J., Jakoby W. B., J. Biol. Chem., 249, 71307139 (1974).

23) Thayer W. S., Biochem. Pharmacol., 33, 2259-2263 (1984).

24) Aebi H. E., "Methods in Enzymatic Analysis," ed. by Bergmeyer H. U. 1974, pp. 673-678.

25) Allen C. T., "Laboratory Methods in Histochemistry," 1st ed., ed. by Prophet E. B., Mills B., Arrington J. B., Sobin L. H., American Registry of Pathology, Washington, DC., 1992, p. 53.

26) Tariq M., Morais C., Sobki S., Al Sulaiman M., Al Khader A., Nephrol. Dial. Transplant., 14, 923-929 (1999).

27) Houghton D. C., Hartnett M., Campbell-Boswell M., Porter G., Bennett W., Am. J. Pathol., 82, 589-612 (1976).

28) Humes H. D., Kidney Int., 33, 900-911 (1988).

29) Laurent G., Kishore B. K., Tulkens P. M., Biochem. Pharmacol., 40, 2383-2392 (1990).

30) Powell J. H., Reidenberg M. M., Biochem. Pharmacol., 32, 3213 3220 (1983).

31) Simmons C. F., Jr., Bogusky R. T., Humes H. D., J. Pharmacol. Exp. Ther, 214, 709-715 (1980).

32) Williams P. D., Holohan P. D., Ross C. R., Toxicol. Appl. Pharmacol., 61, 243-251 (1981).

33) Walker P. D., Shah S. V., Am. J. Physiol., 253, C495-499 (1987).

34) Ramsammy L., Ling K. Y., Josepovitz C., Levine R., Kaloyanides G. J., Biochem. Pharmacol., 34, 3895-3900 (1985).

35) Yang C. L., Du X. H., Han Y. X., Ren. Fail., 17, 21-26 (1995).

36) Ademuyiwa O., Ngaha E. O., Ubah F. O., Hum. Exp. Toxicol., 9, 281288 (1990).

37) Abdel-Gayoum A. A., Bashir A. A., el-Fakhri M. M., Hum. Exp. Toxicol., 14, 884-888 (1995).

38) Pedraza-Chaverri J., Maldonado P. D., Medina-Campos O. N., Olivares-Corichi I. M., Granados-Silvestre M. A., Hernandez-Pando R., Ibarra-Rubio M. E., Free Radic. Biol. Med., 29, 602-611 (2000).

39) Leonard S. S., Xia C., Jiang B. H., Stinefelt B., Klandorf H., Harris G. 
K., Shi X., Biochem. Biophys. Res. Commun., 309, 1017-1026 (2003).

40) Cronin R. E., Thompson J. R., Miner. Electrolyte Metab., 17, 100105 (1991)

41) Sandhya P., Varalakshmi P., J. Appl. Toxicol., 17, 405- 408 (1997)

42) Du X. H., Yang C. L., Nephrol. Dial. Transplant., 9 (Suppl. 4), 135140 (1994).

43) Sener G., Sehirli A. O., Altunbas H. Z., Ersoy Y., Paskaloglu K., Arbak S., Ayanoglu-Dulger G., J. Pineal. Res., 32, $231-236$ (2002).

44) Shifow A. A., Kumar K. V., Naidu M. U., Ratnakar K. S., Nephron, 85, $167-174(2000)$
45) Parlakpinar H., Tasdemir S., Polat A., Bay-Karabulut A., Vardi N., Ucar M., Acet A., Toxicology., 207, 169-177 (2005).

46) Atessahin A., Karahan I., Yilmaz S., Ceribasi A. O., Princci I., Pharmacol. Res., 48, 637-642 (2003).

47) Pedraza-Chaverri J., Barrera D., Maldonado P. D., Chirino Y. I., Macias-Ruvalcaba N. A., Medina-Campos O. N., Castro L., Salcedo M. I., Hernandez-Pando R., B.M.C. Clin. Pharmacol., 4, 5 (2004).

48) Singh D., Chander V., Chopra K., Toxicology., 201, 1-8 (2004).

49) Kumar V., Kotran R. S., Robbins S. L., "Pathologic Basis of Disease," 6th ed., Chap. 1, ed by Kumar V., Cotran R. S., W.B. Saunders Company, Philadelphia, 1999, pp. 15-18. 